\title{
Form Follows Function; Act Follows Form How the Form and Shape of Our Objects Affect Our Behaviour
}

\author{
István Frigyes Váli* \\ ${ }^{1}$ Department of Graphics, Form and Design, Faculty of Architecture, Budapest University of Technology and Economics, \\ H-1521 Budapest, P.O.B. 91, Hungary \\ * Corresponding author, e-mail: vif@rajzi.bme.hu
}

Received: 09 May 2018, Accepted: 24 October 2018, Published online: 03 December 2018

\begin{abstract}
The objects we plan, form and shape also shape our lives. From the smallest human-made objects such as a city map to the biggest such as a city, they all have a bearing on our lives. They make a major impact on the way we feel and on our physical and mental health. This paper approaches the matter through different examples, primarily looking at the effects made by the form and shape of objects. A look at the use of our everyday objects shows in what ways and to what extent the different planning methods and principles may affect our habits and lives, how they serve society and what unexpected side-effects they may have at times. Harry Beck's Tube Map from 1933, the Legible London way-finding system, and Terminal 3 of Narita International Airport are fine examples of the possible links between the forms and uses of objects. The analysis sheds some light on the importance of cooperation between disciplines, in both planning and architect training.
\end{abstract}

Keywords

environmental graphic design, wayfinding, public transportation network map, mental map, spatial orientation, navigation in a built environment

\begin{abstract}
1 Introduction
Our objects and devices affect us and may even radically change our lives. They can be really small like a map or a mobile phone, but they can also be as big like a building or a city. We use and create these objects for ourselves and they, in turn, shape us. Some new inventions have left a deep mark on human history, not only from an economic and political point of view but also regarding the relationships between people. The invention of the wheel and railway has not only saved us considerable economic effort but has also broadened the "scope" of individuals and hence transformed the system of their social relationships. These links include "social media", which are not palpable objects but as such keep changing the forms of human interactions and even people's spiritual reality and feelings before our eyes (Tromholt, 2016). ${ }^{1}$ With the development
\end{abstract}

1 The effects of social media have been analysed and explored by various research projects. One of the best known phenomena is "Facebook envy". An illustrative picture of the effect of social media on our general feeling is provided by Morten Tromholt's research "The Facebook Experiment", conducted in 2015 by the Department of Sociology at the of our objects, we need to make less and less effort to exert an increasing impact on the surrounding world. It is fair to say that our devices are making our lives increasingly easy, but that is just part of the truth as a new device not only provides help but also generates new problems. With the use of smart devices, we are losing competences and are even undergoing physiological changes. Moving on to the subject of this paper, let us take the use of GPS navigation as an example. While it may help us to find a destination with greater ease, we rely on the display of our phone or GPS device and hence fail to build the mental map that we would by getting verbal directions while using a map or by experiences. By using a GPS device, we do not use the hippocampus, the part of the brain responsible for spatial orientation. We are only instructed to go straight, turn right or left but other than that we get very little information. Leaving the hippocampus without a job may result in atrophy and may make us more prone to such conditions as

University of Copenhagen in cooperation with the Danish Happiness Research Institute. 
Alzheimer's disease (Maxwell, 2013). Also, by neglecting maps, we lose the possibility of using the surrounding visible landmarks, relief, and buildings for orientation, and hence of getting additional information through the map and vision, and of coming to understand the spatial structure that surrounds us. The latter would also be important because people with a clear perception of their situation in their environment will have a better general feeling and sense of comfort; their knowledge will enable them to evaluate their environment better and perceiving it as their own that exists for them. Thus, the use of objects has a highly diverse effect on us as their users. The preceding examples refer to abstract concepts such as non-physical objects like "social media", GPS navigation, and the map in general. As soon as an object takes shape and adopts a specific form, such form will also contribute to its effects.

\section{Narita Airport Terminal 3}

As designers and architects, we know the resources that we can use for work. At least, that is what we suppose. The design of an object is fit for its intended uses, but such uses may also become fit for the properties of the given object. There is a difference between grabbing a fragile china cup and a thick-walled beer mug. When walking on an old wooden floor, the dynamic burden of your steps may cause the glasses in the kitchen cupboard to shake and clink; as a result, you start to take softer steps. Well-designed objects suggest the right way to use them, and they refer to their function. The good designer makes sure the user will perceive, recognise, and interpret the purpose of the object and its ways of use (Norman, 2013). Designers must keep many things in mind. In this increasingly complex world, they must keep yet more things in mind. They need to integrate the theory and practice of an increasing number of trades in the decisions of design processes. For instance, for a building's way-finding system to work properly and for people to find their way in such building, it is not enough to have a system of symbols, boards, and signs planned by a graphic designer. The architect must also apply all possible resources. The building's users may be helped in spatial orientation with clear and transparent spatial management, routes, an inner space that communicates with the environment, with the appropriate use of lights, and a host of other factors. If we enable people inside the building to look out on the surrounding world from time to time, we not only give them a point of reference for orientation but also raise their comfort level. This may mean that users simply feel better, but it may also mean that we reduce their stress. It may be hard and frustrating for people to find their way in a strange environment, especially when they are not walking in a wonderful city during their holiday but are in a hurry to catch their connecting flight at a major airport.

By providing the right amount of information in the right place at airports and railway stations, we may help people to find their ways, facilitate their decision-making, reduce their sense of being lost, and all in all, reduce the level of stress that they are exposed to, and hence improve their comfort. Driven by the idea of a "low cost" airport, the designers of the new terminal at Narita International Airport in Chiba Prefecture, Japan, which serves the traffic of Tokyo (ArchDaily, 2015), did not plan the usual travelators and lighted directional signs but created a visual conception that is both user-friendly and refers
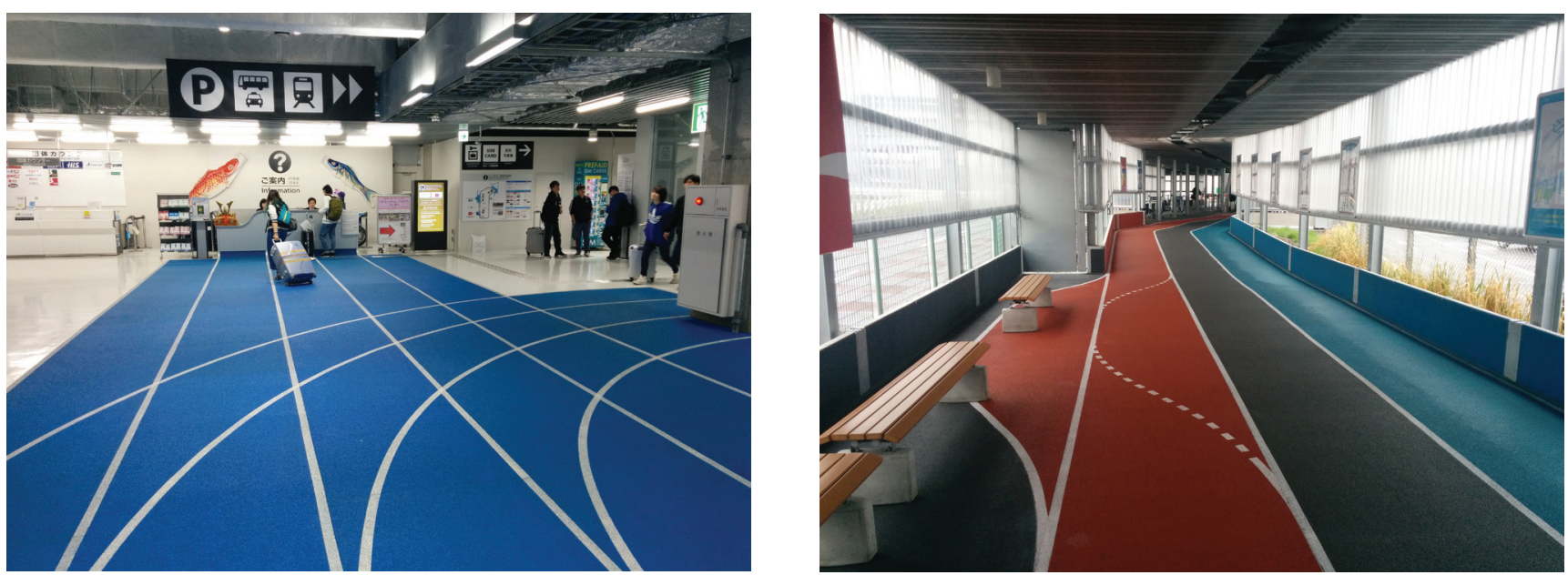

Fig. 1 Narita International Airport Terminal 3. Colour-coded running tracks as the part of the clear information design of the terminal. Photographs by Tyuvc (Wikimedia Commons) 
to the Tokyo Olympics to be held in 2020. In the plain interior, which is not overburdened with signs and information, people can find their way by going along colourcoded running tracks. The blue track leads departing passengers, and the red track leads arriving passengers all the way to their destinations. People are helped by simple, elegant wall-mounted signs and texts at the junctions, and most importantly, by the confirmations along the running tracks. The visually plain inner spaces and readily understandable directions alone do a lot for the improved comfort of airport users, but the marked design and the running tracks even give them a special experience.

The new terminal at Narita Airport is a fine example of the way in which the form of an "object" can make a positive impact on the psychical condition of its user. By facilitating efficient orientation, we can reduce stress and frustration, and can even influence specific physiological processes in a positive way. A passenger who cannot find their flight may experience hypertension, and their nervousness and running may cause hyperventilation. This subject is discussed comprehensively by Carpman and Grant (2002). However, our objects and built environment may have more than just incidental effects. A well or poorly designed neighbourhood or even a suburban map can influence the way in which the inhabitants of an entire city behave for decades. People do not avoid or run through a living city but use and enjoy it. In recent years, urban planning has witnessed a paradigm shift. The approach where motoring is the primary method of transport with the subordinated role of pedestrians and cyclists is slowly disappearing. There are many reasons for this including the need for a living city, sustainability as a new expectation, people's health, and public security. Such needs can be satisfied with resources in architecture, road planning, traffic management, and urban administration. Street walls with soft edges can create a framework for human existence (Gehl, 2014), but this may not be enough if pedestrians do not appear in that area for some clear or even mysterious reason.

\section{Harry Beck's London Tube Map and the Legible London Project}

Public transport in a city is great provided that it replaces motoring, which is less efficient, takes up considerably more space regarding the number of passengers, and pollutes the environment more. At the same time, there is a form of transport which is even better: walking and cycling. They are healthier and have a minimal polluting effect (worn shoes, emission by bicycle manufacturing). They make the city liveable with human presence, hence improving its level of security. In certain distances, they are even faster than public transport, where people must wait for the connections, get stuck in a traffic jam, or go downstairs to suburban stations and then back upstairs. Despite a dense network of lines, London's public transport has become overcrowded in recent years. Many passengers unduly use the Tube for short distances and with unnecessary transfers instead of getting off at the right place and taking a shortcut to their destinations on foot (Turner, 2010). A survey conducted between 2005 and 2007 identified the causes. London's topography does not favour simple orientation as it lacks urban management routes similar to the avenues and boulevards in Paris or Budapest, and it lacks the same relief as Budapest with a flat area in Pest and a range of hills in Buda. Its streets are not arranged in a grid like in Chicago and not even street names help as the numbered streets in New York. This has been exacerbated by the poor efficiency and often misleading design of the pedestrian sign systems. As a result, people find it hard to build a mental map that could help them find their way. Most of the preceding factors cannot be changed. They are conditions that will stay the way they are due to London's inertia and may be impractical even to attempt to change. At the same time, altering the wayfinding system may offer a solution to managing the problem. One of the reasons for the overuse of the Tube is the already classic London underground map itself with its otherwise fascinating graphic design.

\section{Harry Beck's Tube Map}

Before the 1930s, the map of underground lines was projected onto the map above them. This was useful as people knew the city's surface structure and hence used the map as guidance for finding their underground stations and planning their trips. However, with the increasing number of new underground lines, the city centre was ever more densely filled with stations as opposed to the sparsely filled peripheries. Harry Beck, the electrical draughtsman of the London Underground, proposed a map to show the transparency of the line network, the mutual relations between the lines, and the possible transfers. For his idea, he chose the language of his trade, coding and simplification. He used colour coding for the lines, replaced the curves with rectangles and 45-degree diameters, and indicated equal distances between the stations to fit the information in the inner part with a denser network (Jenny, 2006). He used few but clear 
symbols. With these simplifications, he revolutionised the representation of public transport lines. His principles were adopted not only by urban public transport companies but also airlines and shipping companies as he tackled the task as a clear-cut diagram or infographic. Initially, the underground company's management had reservations about this radically new concept, but the first edition in 1933 became a huge success. The map was perfectly fit for its purpose as passengers readily understood the links between the lines. By contrast, such maps distort the distances, leaving customers without a clue as to the actual distance between two stations. Therefore, people now prefer longer trips and transfers to a direct approach on foot to reach their destinations. In a way, Londoners have given up walking because of Beck's map. This does not decrease the value of Harry Beck's iconic work. The intended purpose was perfectly served by his now

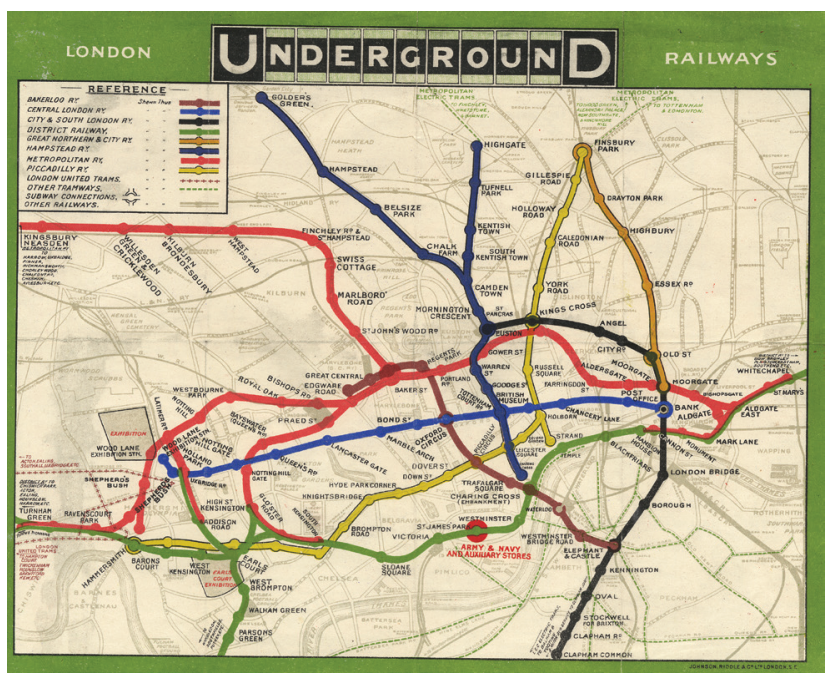

Fig. 2 Pocket Underground map, 1909.

Source: (C) TfL from the London Transport Museum collection

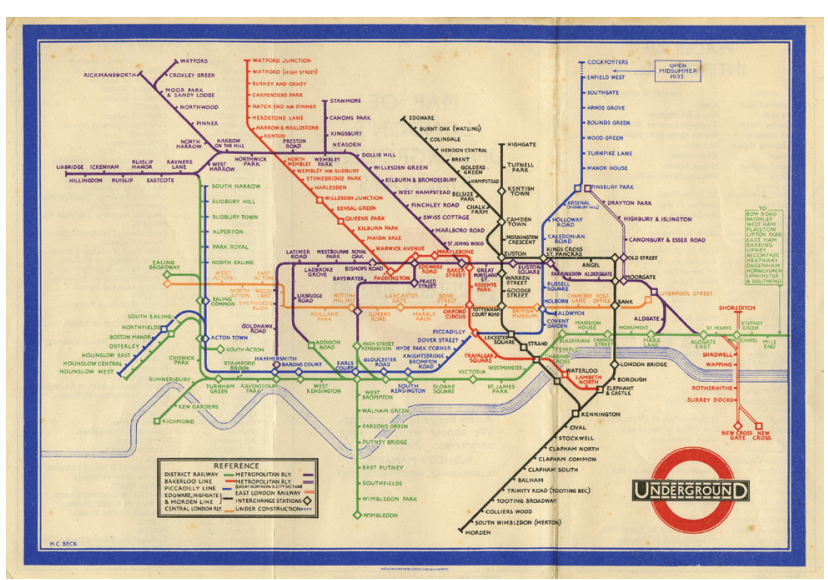

Fig. 3 Harry Beck's London Tube Map, 1933 Source: (C) TfL from the London Transport Museum collection classic design, one of the best-known elements of the brand of the City of London. Beck's map is readily legible but does not support a broader visualisation of the city.

\section{Legible London ${ }^{2}$}

The City of London's management and Transport for London launched a joint research and development project both to reduce the excess burden on the underground network and to make London a healthier, more liveable and less polluted city. The answer to the question became the aptly called Legible London, an urban wayfinding system. The management system of the city's pedestrian traffic is completely different from one inside a building. At an airport, users must be supported in quick decision-making to help them reach their destinations as soon as possible. By contrast, in an urban setting, the way-finding system can also be regarded as a well-informed companion that may provide us not only with key information but also with route options and information about the area such as sites, curiosities and shops. In other words, in the sense of environmental Graphic Design, it can be used for wayfinding, storytelling, and place-making purposes. This shows that these projects are more complex in content and form, and hence their possibilities are different. It takes a host of factors to make the project successful. One of them, of course, is that it must reach the most people and another is that the project must have a content and form that best serve the intended purpose. We have plenty of possibilities for ensuring availability: maps displayed at stations and stops, printed versions for city folks and tourists. The content factors have largely been listed above. By contrast, the form in which contents take shape is perhaps the most important part of the whole project, just as we have seen in the case of Beck's Tube Map. In order to make people willing to walk, it is not enough to put a map in front of them. The map must be such that it helps them identify the spatial relations of their environment, build their own mental maps, which include not only their respective routes in the strictest sense but also the broader environment, and the map must even help them change their habits. Of course, this takes more than a sophisticated and up-todate design. Contents must be presented in a form that is readily understandable and removes all hurdles from the

2 Legible London: a multiple award-winning information design. Its design standards have been adopted by many metropolises worldwide. Design Firms: Applied Wayfinding (former AIG / Applied Information Group), Lacock Gullam. 


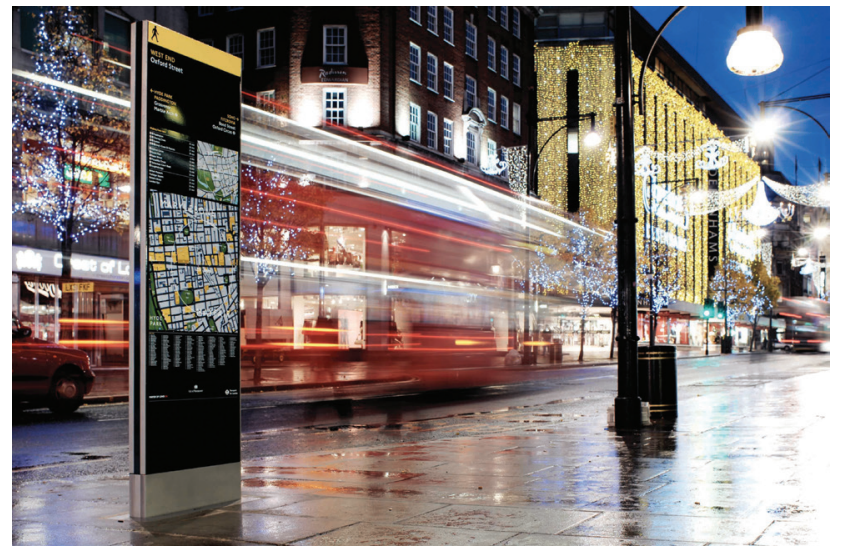

Fig. 4 Legible London, On-street monolith.

Source: Photo copyright (C Philip Vile / Applied Wayfinding (2007)

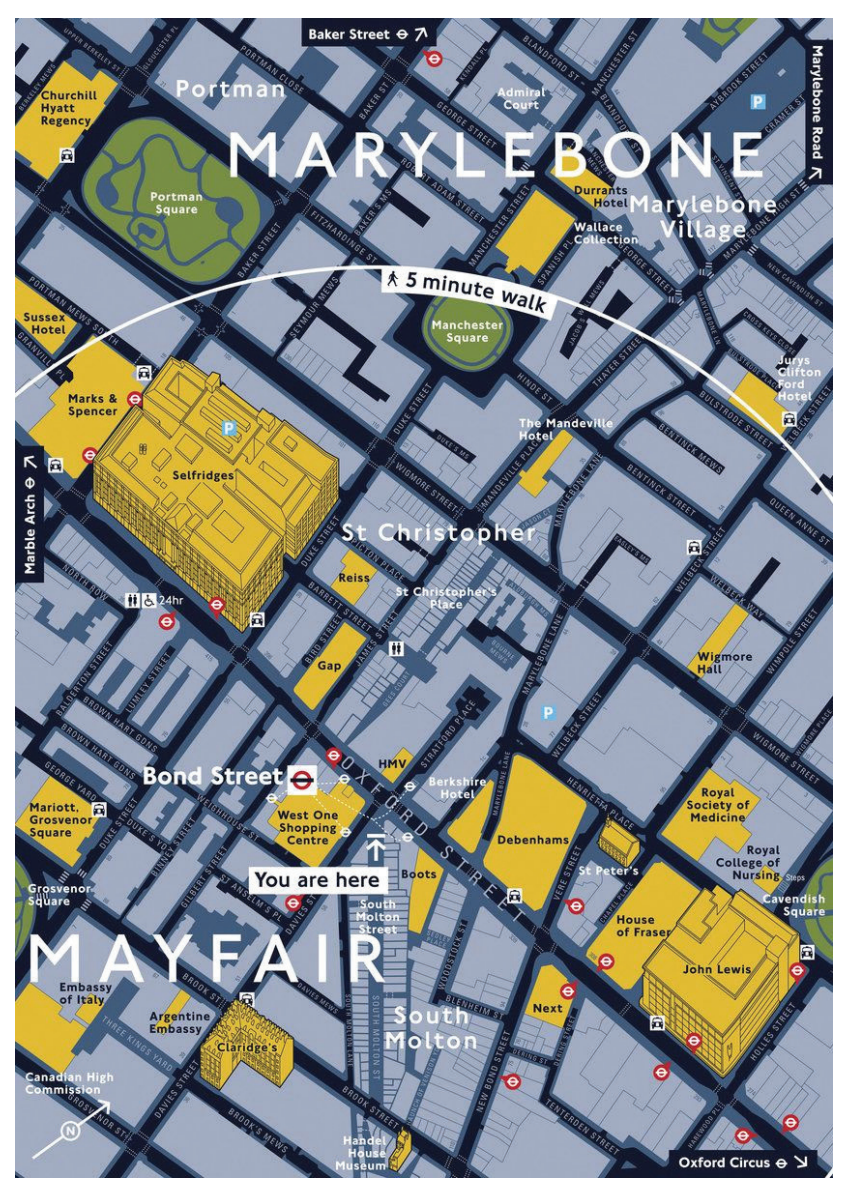

Fig. 5 Legible London, Map detail with "5-minute walk circle" around the "You Are Here" point

Source: Photo copyright (C Philip Vile / Applied Wayfinding (2007)

way of estimating distances and encourages users to walk. An appropriate means to achieve this is the use of cartographically accurate and proportionate map sections, street names, and the textual and graphic representation of curiosities in the neighbourhood. None of these alone is a revolutionary innovation. The novelty is the range of a 5 (15) minute walk drawn around the "You Are Here" point, which shows how far a 5 (15) minute walk can take you. This enables map users to decide right away if it is worth going downstairs to the underground for a trip more than simply walking from one point to another. Those preferring a walk can have experiences they would never have underground. They can walk outdoors without getting in a bothersome crowd, look at shop windows, and catch the smells from local bakeries. They can see people and life while the walk benefits both their soul and bodies (Davies, 2007; Tromholt, 2010).

Moreover, do not forget the city's benefit. People using the streets make the city livable and pollute the air less. Time and motion on the ground promote a better understanding of the city, which reduces our psychical burdens. The things we know will feel more like ours, and hence we will take care of them better and appreciate them more. Completed by the London based design company Applied Wayfinding (former AIG / Applied Information Group), the Legible London project met all expectations, and is working well; Londoners have started to walk, and their positive experiences make many of them walk not only the necessary or logical distances but even more than that (Davies, 2007; Tromholt, 2010).

\section{Conclusion}

The preceding examples have shown the effects that our environment and objects have on us, our lives, including our physical and spiritual health. We have also observed that not only an object as a function devised for a task but also its form may cause profound changes in our lives, lifestyles, and hence even in our health. The examples of the London Tube Map and the Legible London Project also reveal that urban administrators and planners need to deal not only with buildings and roads but also with the graphic design of the little map in our pockets. This complexity, diversity or even sophistication is characteristic of this period and may, unfortunately, fragment our resources. We must strive to manage planning tasks in a holistic way and with circumspection. These experiences must draw the attention of design students to the cooperation of various disciplines, such as urban planning, graphic design, psychology, and to the need to be familiar with their results. As professor Frigyes Pogány, the late Hungarian architect, wrote in his magnum opus The Beautiful Human Environment: "... to us, our space that we mould, form, shape and live, has a centre: man. Thus, we must form man's environment so that it will form people in turn." (Pogány, 1976). 


\section{References}

ArchDaily (2015) "Narita International Airport Terminal 3 / NIKKEN SEKKEI + Ryohin Keikaku + PARTY", [online] Available at: https://www.archdaily.com/620345/narita-international-airport-terminal-3-nikken-sekkei-ryohin-keikaku-party [Accessed: 21 March 2017]

Carpman, J. R., Grant, M. A. (2002) "Wayfinding: A Broad View", In: Bechtel, R. B., Churchman, A. (eds.) Handbook of Environmental Psychology, 1st ed., John Wiley \& Sons Inc., New York, USA, Chapter 28, pp. 427-442.

Davies, J. (2007) "Legible London - Yellow Book - A prototype wayfinding system for London", 1st ed., Transport for London, London, United Kingdom.

Gehl, J. (2014) "Élhető városok", (Cities for People) 1st ed., Terc, Budapest, Hungary. (in Hungarian)

Jenny, B. (2006) "Geometric distortion of schematic network maps", The Bulletin of the Society of Cartographers, 40, pp. 15-18.

Maxwell, R. (2013) "Spatial Orientation and the Brain: The Effects of Map Reading and Navigation", [online] Available at: www.gislounge.com/spatial-orientation-and-the-brain-the-effects-of-mapreading-and-navigation/ [Accessed: 21 March 2017]
Norman, D. (2013) "The Design of Everyday Things", Revised and expanded ed., Basic Books, New York, USA.

Pogány, F. (1976) "A szép emberi környezet" (The Beautiful Human Environment), 1st ed., Gondolat Kiadó, Budapest, Hungary. (in Hungarian)

Tromholt, M. (2016) "The Facebook Experiment: Quitting Facebook Leads to Higher Levels of Well-Being", Cyberpsychology, Behavior, and Social Networking, 19(11), pp. 661-666. https://doi.org/10.1089/cyber.2016.0259

Turner, J. (2010) "Legible London: Can better signs help people understand an extremely disorienting city?", [online] Available at: http:/ www.slate.com/articles/life/signs/2010/03/legible_london.html [Accessed: 21st March 2017]

Wikimedia Commons "CC BY-SA 3.0", [online] Available at: https://creativecommons.org/licenses/by-sa/3.0 [Accessed: 21 March 2017] 